\author{
Cadernos de \\ ESTUDOS LINGḯĺITICOS - (57.1), Campinas, Jan./Jun. 2015
}

\title{
AVANÇO NO ESTUDO DA MUDANÇA SINTÁTICA ASSOCIANDO A TEORIA DA VARIAÇÃO E MUDANÇA E A TEORIA DE PRINCÍPIOS E PARÂMETROS*
}

\author{
MARIA EUGÊNIA L. DUARTE \\ $\mathrm{UFRJ} / \mathrm{CNPQ}$
}

\begin{abstract}
RESUMO: $\mathrm{O}$ artigo se desenvolve em torno de dois pontos principais. $\mathrm{O}$ primeiro consiste no esclarecimento de que a Teoria da Variação e Mudança tem, associado ao componente social, um componente gramatical, que não pode prescindir de uma teoria linguística, o que tem sido tomado como óbvio em diversos estudos da área, uma vez que raramente é explicitado. O segundo mostra que a adoção do quadro teórico de Princípios e Parâmetros, junto com uma refinada descrição da sintaxe das línguas que a Teoria gerativa oferece, foi a alternativa encontrada nos inícios dos anos 1980 para analisar à luz do modelo da Teoria da Variação processos de mudança paramétrica em curso no PB, num momento em que a mudança não entrava na agenda de Princípios e Parâmetros. Feitas as necessárias justificativas sobre tal associação, são apresentados resultados de estudos variacionistas sobre a mudança que envolve a representação do sujeito pronominal no PB. Esses resultados mostram que essa associação permite levantar hipóteses de trabalho e encontrar respostas para as questões empíricas do modelo da Teoria da Variação e Mudança, além de trazer contribuições para a evolução dos estudos teóricos desenvolvidos no âmbito da Teoria de Princípios e Parâmetros.

Palavras-chave: teorias de mudança linguística; teorias linguísticas; Teoria da Variação e Mudança Linguística; Teoria de Princípios e Parâmetros.
\end{abstract}

ABSTRACT: The purpose of this article is twofold. In the first place, I show that the model of study of language change, known as Theory of Language Variation and Change, deeply associated with a social component, implies a grammatical counterpart, usually taken for granted in most of the works carried out under this framework, since it is rarely specified. The second purpose derives from it: the study of syntactic processes of change in course in Brazilian Portuguese has led some researchers to associate the referred theoretical model to study language change with the Principles and Parameters Theory since the early 1980s, when concerns about language change was not in the generative agenda. The remaining of the article presents the development of changes related to the representation of the pronominal subject, emphasizing the advantages of such association to raise hypotheses, to formulate linguistic constraints and to find answers to the empirical problems posed by the Theory of Language Variation and Change. It is also shown that the results bring contribution to the successive refinements concerning the Principles and Parameters Theory.

Keywords: theories of language change; linguistic theories; Theory of Language Variation and Change; Theory of Principles and Parameters.

* Agradeço a um dos pareceristas anônimos valiosas observações no que diz respeito à pesquisa em linguística histórica buscando aplicar ou propor modelos compatíveis com a Teoria Gerativa. Eventuais erros de interpretação são de minha inteira responsabilidade. 
Inicio este artigo com uma breve visita à introdução do modelo teórico para o estudo da mudança linguística, referido como Teoria da Variação e Mudança Linguística, proposto no clássico artigo "Empirical Foundations for a Theory of Language Change" por Weinreich, Labov e Herzog, (1986) ${ }^{1}$, enfatizando sua necessária associação com uma teoria linguística, condição para pôr em prática qualquer modelo de estudo da mudança, desde o levantamento de hipóteses, passando pelos contextos estruturais envolvidos no processo, até a interpretação dos resultados. A seção 2 apresenta as razões que teriam levado à associação de um modelo teórico de mudança que pressupõe a variação intralinguística com uma teoria linguística que assume a invariância na gramática, a Teoria de Princípios e Parâmetros (Chomsky, 1981, e trabalhos subsequentes). Em 3, menciono o surgimento, em fins dos anos 1980, inícios de 1990, de outro modelo de estudo da mudança, compatível com os pressupostos teóricos da Teoria Gerativa - o modelo de Competição de Gramáticas - e levanto algumas questões sobre seu pressuposto básico. A seção 4 apresenta um exemplo do avanço que conseguimos com tal associação no estudo da mudança sintática relacionada à representação do sujeito pronominal no português brasileiro (PB), que tem permitido responder aos problemas ou questões colocados pela Teoria da Variação e Mudança. Finalmente, concluo o artigo com algumas considerações sobre a efetiva contribuição para o próprio refinamento da Teoria de Princípios e Parâmetros trazida por essa associação.

\section{COMO ERA VISTO O PORTUGUÊS BRASILEIRO ANTES DA SOCIOLINGUÍSTICA?}

As imensas diferenças observadas entre a língua nossa de cada dia e as normas repetidas nas gramáticas tradicionais eram explicadas pela "natural" distância entre fala e escrita, ou seja, seriam simplesmente resultantes do fato de que a fala é, em geral, mais espontânea, menos planejada, e a escrita é, em geral, mais formal (o que ninguém pode negar), ou, pior ainda, que o uso de algumas formas na escrita ou na fala mais monitorada, mais planejada era apenas uma questão de "adequação" linguística. É surpreendente que isso ainda seja repetido sem que se reflita sobre a presença de traços gramaticais ausentes da nossa língua-1 e adquiridos (ou aprendidos) durante o processo de escolarização ou por meio do contato frequente com a leitura. Não reconhecer que o termo "adequação" usado nesse sentido sugere que um indivíduo que não aprendeu a usar o verbo haver, os clíticos acusativo e dativo para referência à terceira pessoa, o clítico indefinido ("se"), a ênclise em contexto inicial, entre outros traços ausentes dos dados linguísticos primários a que a criança é exposta, não é capaz de adequar sua fala em situações mais formais (um analfabeto falando com um superior, por exemplo, é plenamente capaz de se adequar ao contexto sem usar qualquer

\footnotetext{
${ }^{1}$ O clássico artigo está traduzido por M. Bagno e publicado pela Parábola Editorial (2006), com prefácio de Faraco e posfácio de Paiva e Duarte.
} 
uma dessas formas; basta ser educado e reconhecer o tipo de situação em que se encontra). Confundimos, pois, "adequação", que qualquer falante com um mínimo de educação pode seguir, com "mudança de gramática", que só o letrado, com prática, pode exibir. ${ }^{2}$

A chegada de Anthony Naro ao Brasil, no início dos anos 70, constitui um marco na pesquisa sistemática que nos permitiria começar a compor uma fotografia da gramática do português brasileiro, a partir justamente da constituição da Amostra MOBRAL (Movimento de Alfabetização Brasileiro), em um projeto coordenado em parceria com Miriam Lemle (Lemle e Naro, 1977). As primeiras dissertações orientadas por Naro, inicialmente na PUC-RJ, com base na referida amostra MOBRAL, se centraram justamente em fenômenos morfossintáticos, entre os quais o estudo das estratégias de relativização (Mollica, 1977), as realizações do acusativo anafórico (Omena 1978) e o uso variável de marcas de concordância no Sintagma Nominal (Scherre, 1978; Braga, 1978). Esses estudos, com base na fala de adultos em fase de aflabetização, mostraram que a língua 1 do brasileiro sem acesso à escola (a) não exibia relativas "padrão", nas funções em que o constituinte relativo tem uma função preposicionada, restringindo-se a relativas "cortadoras" (responsáveis pelo maior percentual de ocorrências) e "copiadoras"; (b) não exibia o qualquer ocorrência do clítico acusativo para referência á terceira pessoa, preferindo uma "categoria vazia", ou objeto nulo, muito mais frequente do que o uso do "pronome nominativo", de ocorrência bem inferior, ao contrário do que supõem os que legislam sobre a gramática do português do Brasil; (c) que a ausência de marcas de concordância nos modificadores no interior do SN era muito frequente e passível de sistematização.

Tais estudos variacionistas, que teriam sido suficientes para que os brasileiros contestassem as restrições de Lavandera (1978) sobre os limites de uma variável sintática, inspirariam inúmeras outras pesquisas que viriam a ser desenvolvidas nos anos 1980 pelos pesquisadores do Projeto PEUL (Programa de Estudos sobre o Uso da Língua) na UFRJ, sob a orientação de Naro, década em que a utilização do modelo de estudo da variação se espalharia pelo Brasil contemplando fenômenos fonético-fonológicos e morfossintáticos.

Desde os estudos pioneiros, todos os trabalhos realizados associavam os pressupostos da Teoria da Variação e Mudança a uma teoria linguística, fosse a Teoria Funcionalista para os estudos morfossintáticos - utilizada nas dissertações mencionadas acima, fossem diferentes teorias fonológicas, morfológicas, semânticas, condição sine qua non para levar a efeito a aplicação do modelo teórico para estudar a mudança ${ }^{3}$. Isso, entretanto, foi tomado como óbvio e nem

\footnotetext{
${ }^{2}$ Remeto o leitor a Pagotto (1998; 2001; 2013), que nos oferece discussões preciosas sobre como foi codificada a norma escrita no Brasil na virada do século 19 e como um discurso pretensamente científico advogou em favor de uma gramática lusitana, pregando que os "brasileirismos" seriam "toleráveis" na fala mas nunca na escrita! Infelizmente, depois de tantos resultados de pesquisas realizadas à luz da Teoria da Variação e Mudança, esse discurso impressionista ainda persiste.

${ }^{3}$ A propósito, os estudos de Labov, com destaque para sua dissertação de mestrado e tese de doutorado aplicaram a Fonologia Gerativa para pôr em prática o modelo da Teoria da Variação e Mudança.
} 
sempre era explicitado nos trabalhos. Essa associação, contudo, não escapou aos olhos atentos de Moura Neves (1999), que, ao relatar o trabalho variacionista desenvolvido no âmbito do Projeto PEUL, ressalta a utilização de diferentes correntes da Teoria Funcionalista. A falta de uma teoria linguística, seja ela advinda das limitadas descrições que nos oferece a tradição gramatical ou de diferentes teorias linguísticas contemporâneas, não permitiria sequer a definição da 'variável', o levantamento de grupos de fatores linguísticos e de hipóteses de trabalho. Esses fatores têm de provir de uma ou mais de uma teoria da linguagem, a depender do fenômeno estudado; e essa teoria ou teorias escolhidas é que vão permitir que o trabalho variacionista vá além de um conjunto de tabelas incapazes de conduzir o pesquisador a respostas para os problemas colocados por W, L \& H, em seu modelo de estudo da mudança. Em um artigo de 2006, Pagotto deixa muito claro que "qualquer abordagem que se diga sociolinguística e não se proponha a dar uma resposta satisfatória à questão de como a estrutura linguística se engendra na estrutura social está, de saída, claudicante com relação às tarefas que propõe investigar" (op. cit: 52). Este talvez seja o texto em que ficam mais claras não só as áreas que a Sociolinguística abrange (entre as quais está a Teoria da Variação e Mudança) como também a importância do componente gramatical associado necessariamente ao componente não-linguístico, nas suas dimensões espacial, social, contextual e temporal (ou histórica). Esta é, pois, uma leitura obrigatória a quem se dedica ao modelo de estudo da mudança aqui abordado.

\section{POR QUE O CASAMENTO DO MODELO DE ESTUDO DA MUDANÇA SINTÁTICA À LUZ DA PROPOSTA DE W, L \& H COM A TEORIA LINGUÍSTICA GERATIVA FOI NECESSÁRIO?}

A chegada de Fernando Tarallo ao Brasil, após seu doutorado na Universidade da Pennsylvania (Philadelphia), em 1983, trazendo em sua bagagem, junto com os resultados de sua tese, o desejo de aplicar o modelo variacionista à análise de fenômenos sintáticos sugerindo mudança em curso no português brasileiro (PB) dentro do contexto das línguas românicas, levou-o inevitavelmente à busca de uma teoria que permitisse diagnosticar, nos fenômenos em variação no $\mathrm{PB}$, reflexos do que caracterizava os parâmetros propostos no âmbito da teoria gerativa. Tarallo sabia muito bem que, para entender as mudanças sintáticas atestadas na sua tese de $1983 \mathrm{e} \mathrm{em}$ diferentes estudos que ele e seus alunos viriam a desenvolver, não podia prescindir de uma teoria linguística que lhe oferecesse um meio de interpretar mudanças superficiais e associá-las a uma mudança subjacente mais abrangente. Afinal, quem quer seguir com coerência o modelo variacionista não pode fugir às cinco questões propostas por W., L. \& H (1968), que devem orientar, guiar o estudo da mudança: as restrições (constraints), a implementação (actuation), a transição (transition), o encaixamento (embedding) e a avaliação (evaluation). Todas essas questões podem e devem ser analisadas à luz de fatores linguísticos e sociais, desde as restrições ou fatores condicionantes, passando pela implementação (que trata da origem e da propagação da mudança), a transição (que observa os estágios do processo, no tempo aparente ou no 
Cadernos de ESTUDOS LINGǘsSTICOS (57.1) - Jan./Jun. 2015

tempo real), até o encaixamento (que busca observar como um determinado fenômeno se relaciona a outros - como se "encaixa" no contexto linguístico e social. A questão da avaliação, que busca captar a percepção do falante e sua reação positiva, negativa ou neutra a certas variantes é, sem dúvida, um forte componente social, que permite prever como se dará a propagação de uma variante inovadora no sistema.

Foi com essa intenção que, em 1987, Tarallo publicou um artigo-manifesto, em que deixa claro seu objetivo de "demonstrar a compatibilidade entre as análises propostas pelo paradigma laboviano e pelo quadro chomskiano" e, antevendo as críticas que se seguiriam, esclarece "que não se trata de romper fronteiras e confundir domínios no sentido de "parametrizar" ou de eliminar diferenças, mas, sobretudo, de enfatizar que eles permitem compatibilizar resultados" em relação às questões então vigentes no âmbito da teoria gerativa com as questões que interessavam à teoria da variação (op.cit.: 55).

O excesso de cuidados de Tarallo, ao propor uma leitura "paramétrica" da variação observada dentro de uma mesma gramática, já que os dados do PB exibiam propriedades relacionadas a uma e outra marcação paramétrica, sugerindo mudança em curso, certamente não teria mais razão de ser nos dias atuais. E nem se justifica o argumento de que a utilização da teoria da variação se transformava numa mera metodologia para a análise de dados. O casamento, formalizado entre Tarallo e Kato $(1989)^{4}$, viria a produzir frutos a partir de análises que permitiriam interpretar processos de mudança em curso no PB, entre os quais mudanças relacionadas ao quadro pronominal e à fixação da ordem SV, reunidas em Tarallo $(1989 ; 1993)$ e em Kato e Tarallo (2003); efeitos da mudança na remarcação (parcial) do valor do Parâmetro do Sujeito Nulo (Kato e Tarallo, 1986; Duarte, 1993, 1995), além de inúmeros estudos sincrônicos e diacrônicos que viriam a ser desenvolvidos sob a orientação ou inspiração de Tarallo e, posteriormente, de Kato (ver artigos em Roberts e Kato (1993) e Kato e Negrão 2000).

Talvez, durante a década de 1980, quando a noção de parâmetros ainda estava "em plena infância", como diz Tarallo (1987:52), num momento em que a teoria gerativa, preocupada com a busca de princípios universais, não se interessava (e nem tinha de se interessar!) pela mudança linguística, fosse natural o espanto diante da tentativa de utilizar uma teoria centrada na "competência" linguística para analisar os dados da língua-E, a "performance" dos indivíduos de uma comunidade de fala, para extrair dali evidências de mudança paramétrica em curso. A crítica mais veemente veio de Borges Neto, em 1988 e publicada em 2004, ${ }^{5}$ sobre a incomensurabilidade

${ }^{4} \mathrm{O}$ artigo, originalmente publicado pela Preedição, foi republicado, com a autorização dos editores, pela Revista Diadorim, Revista dos Programas de Pós-Graduação em Letras Vernáculas, da UFRJ, em 2007.

${ }^{5}$ A crítica de Borges Neto deve ser interpretada dentro do momento histórico em que foi formulada: em 1988, durante uma comunicação apresentada na 40a. Reunião Anual da SBPC). Não tínhamos então outros modelos teóricos para o estudo da mudança. Parece ter faltado na época uma reflexão sobre o fato de o modelo de variação não constituir uma teoria da linguagem; daí sua implementação não poder prescindir de uma. Edições posteriores do referido artigo, como a de 2014, deveriam trazer essa reflexão. 
dos dois modelos teóricos - a Teoria da Variação e Mudança - cujo pressuposto básico era a variação inerente ao sistema, interessada nos dados reais, e a Teoria Gerativa interessada no que era invariável no sistema e centrada no conhecimento do falante, tinha certa razão de ser: parecia mesmo uma heresia! Como compatibilizar teorias com objetos de interesse e pressupostos teóricos tão distintos? Dados empíricos de um lado e a busca da arquitetura da gramática universal de outro!

Mas Tarallo estava interessado em investigar processos de mudança sintática em curso, e, de posse de um modelo teórico de estudo da mudança para tentar desvendá-la - o da Teoria da Variação e Mudança -, viu na Teoria de Princípios e Parâmetros uma proposta de descrição da sintaxe das línguas, da busca dos parâmetros de variação interlinguística, um modelo forte, capaz de lhe fornecer elementos que o ajudassem a achar respostas para suas inquietações - fazer uma leitura "paramétrica" das formas em competição na sintaxe do PB, identificar pistas de mudança em progresso. Afinal, ninguém pode negar que a instalação de uma nova forma no sistema pressupõe variação com uma forma conservadora, sejam elas vistas como variantes de uma mesma gramática sejam elas vistas como pertencentes a gramáticas distintas. E, embora a Teoria Gerativa nos anos 1980 estivesse voltada para a busca de princípios, já se vê em Rizzi (1988), num artigo que só seria publicado em 1997, sob o mesmo título original, a possibilidade de mudança no valor de um determinado parâmetro da gramática universal e um importante insight sobre o poder explanatório do modelo de Princípios e Parâmetros justamente para interpretar a mudança linguística em curso:

"A teoria de pâmetros tem um importante potencial explanatório em relação à mudança linguística, um potencial que os linguistas começaram a explorar em torno dos últimos cinco anos (Lightfoot 1991; Roberts 1992). Se uma propriedade P diretamente ligada a um determinado valor paramétrico muda no curso da história de uma língua, nós podemos predizer que outra propriedade dedutivelmente relacionada a P mudará também” (Rizzi, 1997:277, ênfase acrescida)

Observe-se que Rizzi ressalta que a tentativa de reunir propriedades associadas a uma determinada marcação no valor de um parâmetro da gramática universal fornece ao estudo da mudança a possibilidade de predizer futuras mudanças, caso uma propriedade relacionada a essa marcação paramétrica mude. Em outras palavras, um pesquisador que busca resposta para o "encaixamento" de uma mudança num determinado traço associado a um determinado valor paramétrico, marcado, por exemplo, como [+Sujeito Nulo], pode predizer que outras mudanças esperar em decorrência de uma mudança atestada sugerindo uma remarcação (como, por exemplo [-Sujeito Nulo]) e buscar acompanhar esse percurso, porque o modelo oferece um conjunto de efeitos associados a uma marcação positiva ou negativa. Esta foi a grande motivação da associação proposta por Tarallo e Kato, e alguns dos resultados dessa aplicação serão descritos na seção 4. Naquele momento, naquele contexto histórico, a descrição da sintaxe das línguas, em busca de definir princípios universais e parâmetros de variação entre vas línguas humanas, que viria a passar por inúmeras reformulações (que eu chamaria aperfeiçoamentos), como veremos a seguir, era uma escolha acertada. 
Sem ela, muitas questões e correlações hoje atestadas na observação da sintaxe do PB no contexto das línguas românicas teriam passado despercebidas.

Só a partir do interesse de formalistas pela aquisição da linguagem e pela mudança diacrônica é que a teoria gerativa se voltaria para os dados da Língua-E, tanto aqueles fornecidos pelas crianças em fase de aquisição como os que vinham de textos escritos em outras épocas, e, mais que isso, para a necessidade de lidar com evidências empíricas robustas ${ }^{6}$. Nesse sentido, o trabalho de Lightfoot (1991) sobre aquisição e mudança e o de Roberts (1992) sobre a mudança diacrônica, ambos mencionados na publicação de Rizzi (1997), seriam fundamentais.

\section{A MUDANÇA DENTRO DA PERSPECTIVA GERATIVISTA}

Foi a partir de evidências diacrônicas que a mudança linguística entrou para a agenda dos gerativistas. As discussões de Lightfoot (1991) sobre mudanças que afetaram a posição sintática de SNs com o papel temático de experienciador em função de objeto na história do inglês (com verbos como like, por exemplo), a recategorização dos auxiliares modais (antes verbos plenos) relacionada à mudança envolvendo a perda de movimento de V para INFL, fenômeno largamente estudado por Kroch $(1989,1994,2001)$, buscaram acomodar a variação observada na linha do tempo, como reflexos de diferentes gramáticas, que conviveriam durante um período de tempo, geralmente muito longo, para finalmente se resolver por uma das formas. A mudança se daria durante a aquisição e a nova forma, fruto de uma remarcação no valor de determinado parâmetros, conviveria coma forma antiga até sua completa obsolescência. Tem-se, assim, um modelo que contempla a variação, indispensável para que a mudança se instale num sistema linguístico, mas que não compromete o pressuposto gerativista básico de invariância dentro de uma mesma gramática.

O modelo de "competição de gramáticas" de Kroch busca levantar as restrições, acompanhar a implementação de um traço de uma nova "gramática" no sistema, observando quais os contextos que favorecem e os que retardam sua propagação, além de buscar identificar que mudança subjacente é responsável por um conjunto de efeitos superficiais exibidos durante a competição de formas. Essa busca tem um nome na Teoria da Variação: "encaixamento" da mudança.

No clássico artigo mencionado no início deste texto, W., L. \& H (1968: $101 ; 172$ ) escrevem que "os linguistas desconfiam de qualquer explicação para a mudança que deixe de mostrar a influência do ambiente estrutural sobre o traço em análise". Segundo eles "é razoável supor que um traço esteja envolvido numa matriz linguística que mude com ele" e que é necessário identificar "que outras mudanças se associam a uma mudança específica de uma forma não acidental".

\footnotetext{
${ }^{6}$ É preciso deixar claro que há os gerativistas que continuam a desenvolver seus estudos com base em dados da intuição e não precisam de mais do que isso. No entanto, aqueles que se preocupam com a aquisição e a mudança não podem prescindir dos dados empíricos, a partir dos quais fazem suas generalizações.
} 
Como se vê, essas perguntas são típicas de modelos teóricos para estudar a mudança e não constituem em si mesmas uma teoria linguística que forneça uma descrição da fonologia, da sintaxe ou da semântica de uma língua e que permita identificar as estruturas envolvidas. No entanto, há entre o modelo de W,L\&H e o de Kroch uma diferença crucial: a concepção de gramática. Enquanto um prega que:

...o domínio de estruturas heterogêneas por um falante nativo nada tem a ver com multidialetismo nem com o "mero" desempenho, mas é parte da competência linguística monolíngue. [...] Numa língua que serve a uma comunidade complexa (i.e., real) a ausência de heterogeneidade é que seria disfuncional. (W, L\& H, 2006 [1968]: 100-101, ênfase acrescida)

Outro, tratando da "variação morfossintática" defende que:

..as opções em questão (...) não são realizações alternativas dentro de uma única gramática (...). Antes, elas parecem envolver sempre escolhas gramaticais opostas inconsistentes com a postulação de uma única análise unitária. Uma variação desse tipo não se estabiliza (...) Ao contrário, a língua evolui de tal modo que uma ou outra variante desaparece. Em relação aos "dublês morfológicos", os falantes só podem aprender uma ou outra forma ao longo do processo de aquisição, mas não ambas ao mesmo tempo. A outra forma pode ser adquirida mais tarde como empréstimo, mas de maneira diferente da aquisição da gramática nuclear. (tradução livre de Kroch 1994:183; ênfase acrescida)

Esta não é uma questão trivial e está na causa de toda a polêmica gerada pelo "casamento" do modelo da Teoria da Variação e Mudança (W,L,H) com a Teoria Linguística Gerativa. De fato, o modelo de Competição de Gramáticas de Kroch parece inatacável, especialmente quando se analisa a ocorrência de uma forma extinta da L1 que entra tardiamente na fala via escolarização, em percentuais modestos, e, em índices mais expressivos, na escrita de indivíduos escolarizados (Kato, 2005). Em tais casos, não é difícil encontrar argumentos a favor da competição de gramáticas. A competição entre ter e haver existenciais constitui hoje um exemplo perfeito de gramáticas em competição. O mesmo se pode dizer das realizações do acusativo e do dativo para referência à terceira pessoa e das estratégias de indeterminação. Tanto o verbo haver, quanto os clíticos acusativo (o), dativo (lhe) e indefinido (se) estão ausentes dos dados de aquisição e, consequentemente, não fazem parte da nossa L1, aparecendo em índices muito parcimoniosos na fala dos letrados, especialmente os mais velhos, enquanto na escrita mais padronizada eles chegam a alcançar índices próximos aos da fala lusitana. ${ }^{7}$ Essas ocorrências, particularmente notadas em índices mais expressivos

${ }^{7}$ Sobre a análise de ter e haver à luz do modelo de competição de gramáticas, ver Avelar 2006 e Marins 2013, entre outros. Sobre a ausência dos referidos clíticos na fala de indivíduos de baixa escolaridade, sua limitadíssima ocorrência na fala dos letrados e sua recuperação razoavelmente expressiva na escrita, ver Duarte (2007; 2013), Duarte e Freire (2014), Duarte e Ramos (2015). Berlinck (1996) e Gomes (2003), entre outros, revelam a absoluta ausência do clítico dativo lhe para referência à terceira pessoa, embora ele seja atestado com certa frequência para referência à $2^{\mathrm{a}}$. pessoa, tanto em função dativa quando em função acusativa, em certas regiões (eu não lhe vi). 
na escrita, constituem evidência de uma forma adquirida mais tarde, por influência do modelo escolar, tal como descreve Kroch.

Quando, no entanto, se observa uma mudança em curso, a proposta de gramáticas em competição suscita algumas questões importantes. Uma pesquisadora interessada na aquisição e na mudança, Henry (2002) questiona, no modelo de Kroch, o fato de ele não explicar por que uma nova estrutura, efeito superficial de uma mudança paramétrica (ou da mudança de propriedades formais de núcleos funcionais) não ocorre com a mesma frequência em todos os $\operatorname{contextos}^{8}$. A ênfase do próprio autor no fato de que a mudança não é instantânea, envolvendo a alternância de formas durante um longo período de tempo (a análise de Kroch a que Henry se refere, sobre o aparecimento do "do" perifrástico em inglês, inclui dados recolhidos de textos produzidos entre 1400 e 1550), sugere que gerações sucessivas de falantes adquiririam regras variáveis, que vão, a cada geração, evoluindo a favor da variante nova, até a completude da mudança. Assim, a análise de Kroch apresenta dados em variação, mas conclui que não se trata de verdadeira opcionalidade e sim de gramáticas em competição.

Uma outra questão colocada por Henry diz respeito à aquisição. "Se as gramáticas são naturalmente variáveis, seria natural atestar a variação nos estágios iniciais da aquisição. Se, por outro lado, as gramáticas fossem invariáveis, então esperaríamos que as crianças adquirissem uma única forma e apenas mais tarde uma outra variante, por razões estilísticas ou sociolinguísticas" (Henry, 2002: 278). Em estudos sobre a aquisição do inglês em Belfast, com crianças entre 2 e 4 anos, a autora encontra evidências de que elas não só adquirem regras variáveis mas são sensíveis ao input a que estão expostas, reproduzindo os mesmos índices dos seus cuidadores em relação à variação da não concordância vs concordância com o SN "associado" em construções com o expletivo "there" (there was some flowers in the window vs there were some flowers in the window), entre um SN sujeito plural e o verbo no presente (the books goes on the shelf vs the books go on the shelf) e no uso na dupla negação (he didn't do nothing vs he did nothing).

Estudos importantes sobre a aquisição no português sugerem igualmente que as crianças adquirem regras variáveis no PB. As investigações de Lopes (2003, entre vários outros estudos) centradas na aquisição do sujeito e do objeto mostram que, por volta dos quatro anos, a criança apresenta índices de sujeito expresso ( $v s$ nulo) e de objeto nulo ( $v s$ expresso por meio de pronomes nominativos e DPs lexicais) comparáveis aos do adulto. Resultado semelhante é encontrado por Duarte (2000a) na aquisição do português como L2 por índios de diferentes tribos em contato com os funcionários de um posto da FUNAI (Fundação Nacional do Índio) no Alto $\mathrm{Xingu}^{9}$. Os falantes revelam índices de sujeito pronominal expresso e de objeto nulo muito próximos aos exibidos pelos entrevistados da amostra NURC-RJ, nas

\footnotetext{
${ }^{8}$ Se é fato que, uma vez instalada no sistema, a implementação de uma forma nova se dá a uma taxa constante, o mesmo não se pode dizer de sua entrada nos diferentes contextos estruturais.

${ }^{9} \mathrm{O}$ material foi recolhido por Charlotte Emmerich para sua tese de Doutorado (1984).
} 
análises de Duarte (1995) e de Freire (2000), respectivamente ${ }^{10}$. O único traço ausente da fala dos indígenas é o uso do clítico acusativo (naturalmente também ausente da fala das crianças brasileiras). Sua ocorrência na fala dos mais velhos da amostra NURC-RJ chega a inexpressivos 3\%, um percentual irrelevante para ter qualquer efeito na aquisição. Observe-se que esses falantes cultos, expostos por longos anos ao processo de escolarização, aprenderam o clítico tardiamente, como traço de uma segunda gramática, e não o incorporam efetivamente à sua fala espontânea. O clítico só vai ocorrer em índices mais expressivos, próximos aos da fala lusitana, na escrita mais padronizada (Duarte e Freire, 2014). Quanto à realização do sujeito pronominal, não apenas os índices, mas também os contextos de ocorrência no português de contato do Alto Xingu e na fala culta carioca, são absolutamente comparáveis.

As discussões envolvendo a interpretação da variação - como inerente ao sistema ou como formas de diferentes gramáticas em competição - encontram argumentos em defesa de uma e outra interpretação, mas de forma alguma invalidam os resultados de estudos realizados à luz de um e outro modelo de mudança, sempre lançando mão da descrição sintática e da proposta de Princípios de Parâmetros. Podemos dizer que o que está em jogo nessa discussão é olhar para a mudança na competência e no desempenho do indivíduo e da sua comunidade de fala. Na seção que segue, quando passo a mostrar alguns avanços advindos da associação da Teoria da Variação e Mudança com a Teoria de Princípios e Parâmetros, essa percepção da gradualidade da mudança no desempenho do falante fica evidente.

\section{ALGUNS FRUTOS DE UM "PROJETO HERÉTICO"}

Nesta seção, resumo alguns resultados obtidos no acompanhamento de um processo de mudança envolvendo a representação do sujeito pronominal do PB e o quanto as respostas obtidas para as questões colocadas pelo modelo de variação podem ser creditadas à associação da Teoria da Variação e Mudança com a Teoria de Princípios e Parâmetros. O adjetivo "herético" foi sugerido por Kato (1999), ao apresentar os primeiros frutos do projeto iniciado com Fernando Tarallo.

As investigações pioneiras sobre a representação do sujeito pronominal no âmbito dos estudos linguísticos no PB se devem a Lira (1982), Tarallo (1983), Moreira da Silva (1983) e Paredes Silva (1988). Lira e Paredes Silva, trabalhando, respectivamente, com amostras contemporâneas da fala e da escrita carioca (cartas pessoais), analisaram a alternância sujeito "zero" e pronome expresso, associando o modelo de Variação e Mudança a pressupostos da Teoria Funcionalista, enquanto Moreira da Silva e Tarallo observaram a

\footnotetext{
${ }^{10}$ Não só os índices percentuais são próximos, mas os fatores linguísticos e sociais selecionados pelo programa de regra variável são os mesmos.
} 
assimetria sujeitos pronominais expressos e objetos nulos, o primeiro num trabalho formal, o segundo numa análise empírica com base em cartas escritas em quatro períodos ao longo dos séculos 18 e 19. Em todos esses estudos, ficam evidentes dois movimentos distintos em direção a sujeitos pronominais expressos ${ }^{11}$ e objetos anafóricos nulos no PB, que viriam a ser corroborados em análises posteriores de Duarte (1993; 2000b) para o sujeito e Cyrino (1993; 1997) para o objeto.

Em Duarte (1993), numa tentativa de associar o modelo variacionista a pressupostos gerativistas, iniciei uma investigação da mudança na marcação do valor do Parâmetro do Sujeito Nulo (PSN) no PB, começando pelos sujeitos de referência definida, com base em uma amostra de peças de teatro de caráter popular, escritas por autores cariocas ao longo dos séculos 19 e 20. A hipótese principal que orientou o trabalho era a de que a inserção de duas novas formas no nosso quadro pronominal, em diferentes momentos, você e a gente, ambas originárias de dois DPs, a forma de tratamento Vossa Mercê e o DP coletivo a gente, combinando-se, pois, com a forma verbal não marcada por flexão distintiva - a terceira pessoa do singular - provocaria uma redução no paradigma flexional do $\mathrm{PB}$, o que levaria à perda do princípio funcional que permite a omissão do pronome quando identificado por flexão (Chomsky, 1981). Essa redução no paradigma flexional seria agravada pela provável neutralização entre você e $t u$, no que se refere à perda de distinção no plano da cortesia, e a tendência à queda da desinência canônica $<-\mathrm{s}>$ que marcava a segunda pessoa representada por $t u$. Como se tratava de texto escrito, embora de caráter mais próximo da fala, não foi atestada a ausência de marcas para a segunda pessoa do singular (tu) ou para a segunda e terceira pessoas do plural.

Em (1), encontramos exemplos prototípicos da gramática que caracterizava as primeiras sincronias, com estruturas que ilustram um sistema de sujeitos nulos licenciados e identificados por um paradigma flexional "rico" (Rizzi, 1982), como é o italiano, enquanto em (2) temos ocorrências que caracterizam as sincronias mais recentes da amostra, relativas ao último quartel do século 20, típicas de sistemas que não permitem sujeitos pronominais referenciais nulos em contextos neutros, como o inglês ${ }^{12}$ :

(1) a. Quando $\boldsymbol{\emptyset}_{1 \mathrm{ps}}$ te vi pela primeira vez, $\boldsymbol{\emptyset}_{1 \mathrm{ps}}$ não sabia que $\boldsymbol{\emptyset}_{2 \mathrm{ps}}$ eras viúva e rica. $\boldsymbol{\emptyset}_{1 \mathrm{ps}}$ Amei-te por simpatia. (O noviço, Martins Pena, 1845).

${ }^{11} \mathrm{Na}$ análise de Paredes Silva (1988), o sujeito de primeira pessoa alcança os índices mais altos de sujeito nulo, contrariando as pesquisas sobre a língua oral. Como nas cartas, a primeira pessoa é pressuposta, temos aí um contexto não neutro. Línguas como o inglês, que não exibem sujeitos nulos em contextos neutros, exibem sujeitos nulos em casos em que este é pragmaticamente identificado (cf. Haegeman (1990) sobre a ocorrência de sujeitos nulos em diários; Cote (1996) sobre argumentos nulos em inglês).

${ }^{12}$ Contextos neutros são aqueles em que não há ênfase ou contraste. Além desses contextos marcados, que levam a um pronome expresso, destaca-se também a realização fonética da primeira pessoa, sempre que o falante retoma o curso (cf. Marins (2009) sobre a realização do sujeito pronominal em italiano). 
b. $\boldsymbol{\emptyset}_{2 \mathrm{ps}}$ Terá o cavalo que $\boldsymbol{\emptyset}_{2 \mathrm{ps}}$ deseja. (O simpático Jeremias, Gastão Tojeiro, 1918)

c. Já ontem comprei-[lhe $]_{\mathrm{i}}$ o hábito com que $\boldsymbol{\emptyset}_{\mathrm{i}}$ andará vestido. Assim $\boldsymbol{\emptyset}_{\mathrm{i}}$ não estranhará. Ø Será frade feliz. (O noviço, Martins Pena, 1845).

(2) a. Se eu ficasse aqui eu ia querer ser a madrinha. (No coração do Brasil, Miguel Falabella, 1992).

b. Você não entende meu coração porque você 'tá sempre olhando pro céu e procurando chuva. (No coração do Brasil, Miguel Falabella, 1992)

c. Agora ele não vai mais poder dizer as coisas que ele queria dizer. (No coração do Brasil, Miguel Falabella, 1992)

Os resultados gerais, reunindo primeira, segunda e terceira pessoas, apontavam claro processo de redução gradativa dos índices de sujeitos nulos ao longo dos sete períodos de tempo contemplados ${ }^{13}$. Vejamos a Figura 1.

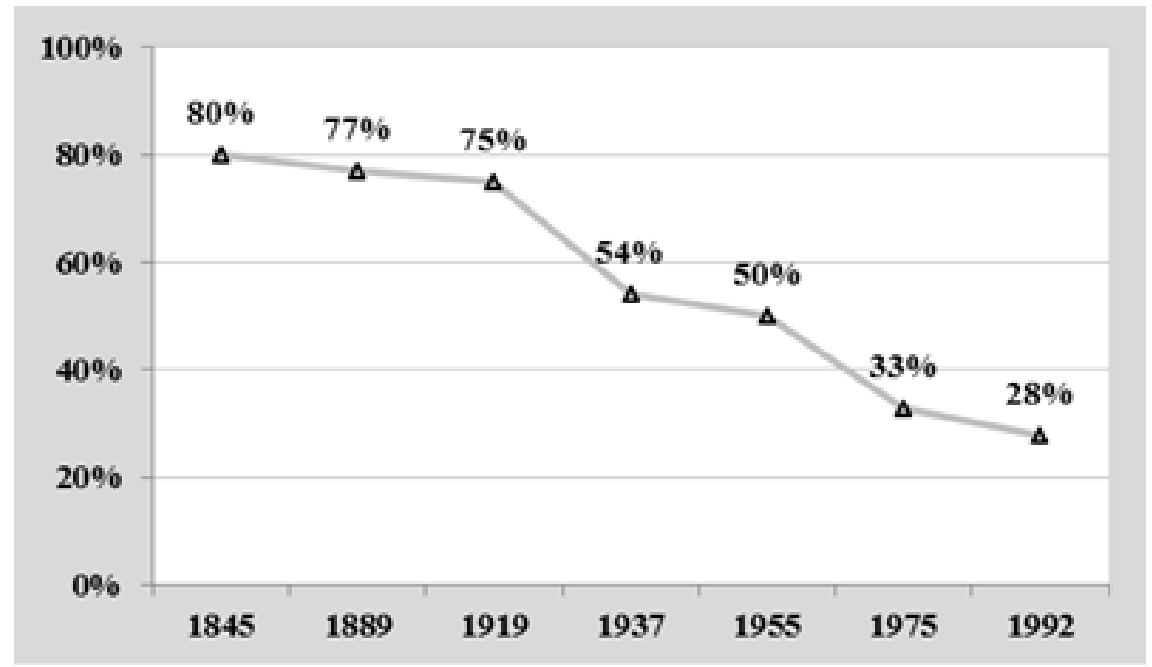

Figura 1. Sujeitos referenciais nulos vs. pronomes expressos ao longo do tempo (Duarte, 1993, Fig. 1:112)

A Figura 1 nos indica que as três primeiras sincronias, aqui identificadas pelo ano da peça de teatro analisada, se encontram muito próximas em termos percentuais e ilustram o que se poderia caracterizar como um sistema positivamente marcado em relação ao Parâmetro do Sujeito Nulo (doravante $[+\mathrm{SN}])$. Assim, a escrita do teatro popular ${ }^{14}$, que seria uma aproximação da

${ }^{13}$ Os dois primeiros dos sete períodos contemplam a primeira e a segunda metades do século 19 , quando o número de autores dedicados especificamente ao teatro era mais escasso, enquanto os demais períodos se distribuem ao longo do século 20.

${ }^{14}$ Todos os autores analisados eram dedicados ao teatro e foram muito populares em seu tempo. 
Cadernos de ESTUDOS LINGǘISTICOS (57.1) - Jan./Jun. 2015

fala urbana carioca durante o século 19 e o primeiro quartel do século 20 , sugere um sistema [+SN]. Os anos 1930 e 1955 representam um momento de transição, coincidindo com a opção pelo tratamento com você, que, nas três sincronias anteriores se encontrava em distribuição complementar com o pronome $t u^{15}$, segundo o tipo de relação entre os interlocutores - simétrica ou assimétrica - o que não impedia a preferência pelo sujeito nulo, independentemente do pronome utilizado. A partir dos anos 1970, com a implementação do pronome $a$ gente, o resultado geral praticamente se inverte, chegando a $28 \%$ de sujeitos nulos.

Observados, entretanto, segundo a pessoa do discurso, uma das mais importantes restrições controladas pelo trabalho, os resultados mostravam que o percurso da mudança gramatical não se dava com a mesma velocidade: enquanto a primeira e a segunda pessoas apresentavam curva descendente sugestiva de mudança praticamente concluída, a terceira progredia mais lentamente. Vejamos as três linhas na Figura 2:

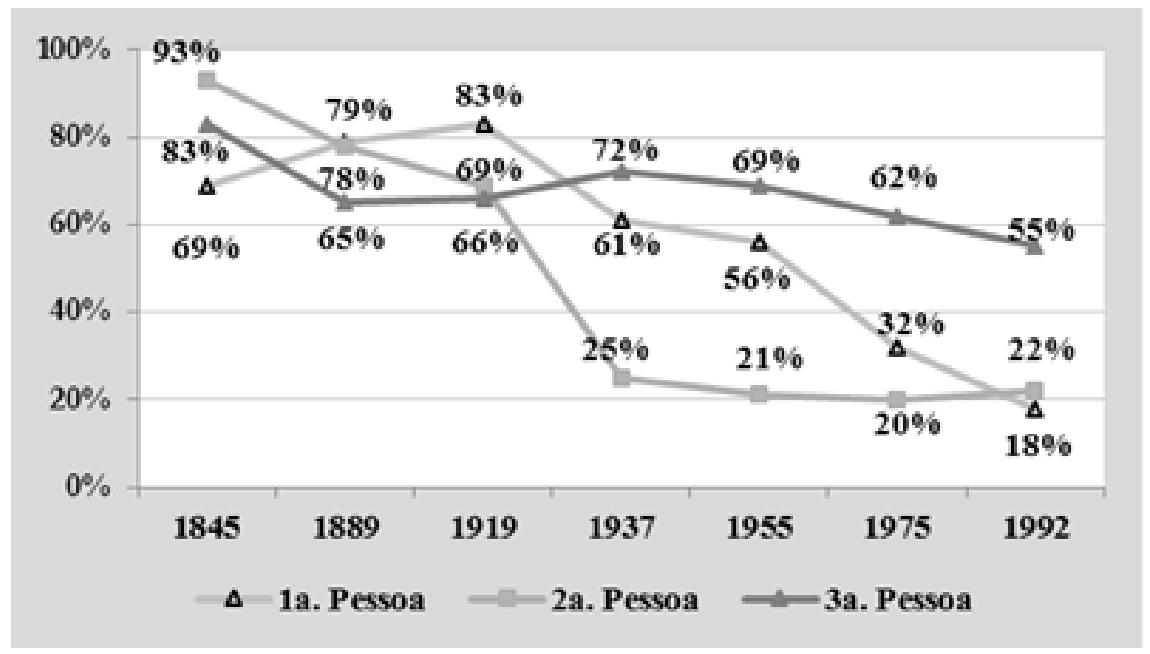

Figura 2. Sujeitos referenciais nulos (vs. pronomes expressos) segundo a pessoa do discurso em peças de teatro (Duarte, 1993, Fig. 5:117)

Nota-se que a primeira pessoa, que apresenta $69 \%$ de sujeitos nulos em 1845 , chega a $18 \%$ em 1992, e a segunda pessoa, que parte de $93 \%$ de sujeitos nulos (as diferenças entre o uso de $t u$ ou outra forma de tratamento são irrelevantes), alcança $22 \%$ no último período. A terceira pessoa, por outro lado, embora apresente curva

${ }^{15}$ Outras peças escritas na mesma época mostram que o pronome tu não desaparece, como ocorreu nas peças da amostra de Duarte (1993), mas passa a ser usado em variação com você já sugerindo a neutralização que viria a se consolidar no PB:

(i) Não sejas bobo menino! Sabe que dia é hoje? (...) Daqui a cinco dias você completa vinte e dois anos. (A vida tem três andares, Humberto Couto, 1938) 
descendente, sai de $83 \%$ e alcança $55 \%$ na peça de 1992 , uma diferença de 28 pontos percentuais contra 51e 71 pontos para a primeira e a segunda pessoas, respectivamente.

A que se deveria esse percurso mais lento dos sujeitos de terceira pessoa em direção ao preenchimento? Uma das respostas, amplamente discutidas desde Moreira da Silva (1983), retomadas em Figueiredo Silva (2000) e por Modesto (2000; 2008), estaria no fato de que um sujeito de terceira pessoa continuava a ser identificado por um antecedente com a mesma função na oração matriz ou por um tópico discursivo, sendo o primeiro tipo um sujeito nulo "anafórico" e o segundo, um sujeito nulo do tipo "variável", usando a teoria de Princípios e Parâmetros na versão da Teoria da Regência e Ligação dos anos 1980. Em Barbosa, Duarte e Kato (2005), uma análise empírica de dados do PE e PB em entrevistas transcritas em jornais e revistas, proporia quatro padrões sentenciais, reforçando as restrições apontadas pelos referidos autores. De fato, a mesma função do antecedente, no mesmo período ou numa sentença adjacente favorece o sujeito nulo de terceira pessoa no $\mathrm{PB}$, enquanto no $\mathrm{PE}$, um antecedente em outra função ou distante não inibe o sujeito nulo, a menos que ele provoque ambiguidade. No quadro atual, como veremos, o sujeito nulo identificado seja por um antecedente na mesma função seja por um tópico marcado (i.e. presente na periferia da sentença) ou um tópico no contexto precedente (discursivo) recebe a mesma análise: é considerado como identificado por um tópico (cf. Modesto, 2008).

De fato, essa é uma restrição que não se vê numa língua [+SN], como mostra o exemplo (1c), em que o sujeito nulo de terceira pessoa tem seu antecedente na função de dativo. Mas, além da função do antecedente, uma outra questão está envolvida na maior resistência dos sujeitos de terceira pessoa e tem a ver também com o seu traço semântico. Com base nos resultados de Duarte (1993) para os sujeitos expressos (aqui referidos) e nos de Cyrino (1993;1997) para o objeto nulo, também obtidos a partir da análise de peças de teatro, Cyrino, Duarte e Kato (2000) concluem que a referencialidade tem grande influência em processos de mudança envolvendo pronomes. Enquanto os sujeitos de primeira e segunda pessoas são inerentemente [+humanos/+específicos], nos de terceira podem se combinar os traços [+/-humano] e [+/-específico]. As autoras propõem, então, uma hierarquia de referencialidade, apresentada a seguir:

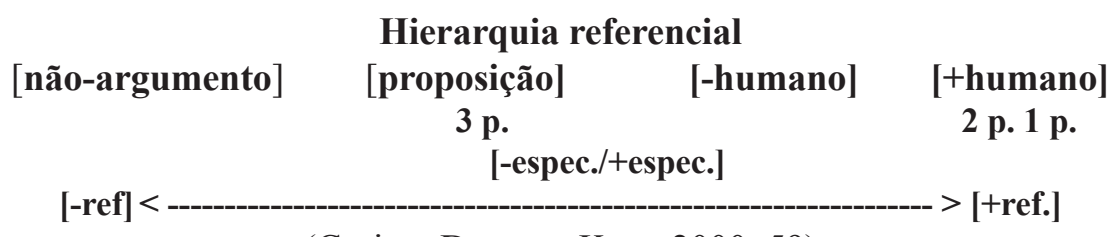

(Cyrino, Duarte e Kato, 2000: 59)

A hierarquia ajuda a entender o percurso dos complementos acusativos nulos, que começam a se implementar a partir dos antecedentes oracionais (ou proposicionais), para alcançar em seguida aqueles com os traços [-hum/-esp], seguindo-se aqueles com os traços [-hum/ +esp]; resistem ao objeto nulo os 
Cadernos de ESTUDOS LINGüÍSTICOS (57.1) - Jan./Jun. 2015

antecedentes com o traço [+humano] ${ }^{16}$. Com o sujeito expresso, se vê o percurso inverso: sujeitos de primeira e segunda pessoas, inerentemente [+hum/+esp], se tornam foneticamente expressos mais rapidamente do que aqueles que se situam em pontos mais baixos na hierarquia.

Estava aí uma explicação adicional para o processo de mudança em curso: o feixe de traços semânticos. E estava aí igualmente uma possível explicação para a maior resistência da terceira pessoa na análise de Duarte (1993). O mesmo resultado seria encontrado para a fala carioca nas variedades culta (Duarte 1995) e popular (Duarte 2003).

Em busca de evidências empíricas que confirmassem a relevância da função e posição do antecedente (ou padrão sentencial, nos termos de Barbosa, Duarte e Kato, 2005) e da interação de traços semânticos, os estudos em Duarte (2012) prosseguem a investigação, desta vez ampliando a amostra de peças cariocas, sem perder as características da amostra inicial, e percorrem a hierarquia referencial, a partir de um refinamento dos sujeitos de terceira pessoa (Duarte, Mourão e Santos (2012), revisitando Duarte (1993). Os feixes de traços são ilustrados a seguir:

\section{[+h/+espec]}

(3) a. Limoeiro : [O tenente-coronel $]_{\mathrm{i}}$ ainda nao veio?

Perpétua : $\varnothing_{\mathrm{i}}$ Está lá dentro.

(Como se fazia um deputado, França Jr, 1882)

b. Maria Lúcia : Laurinha me ligou ontem, de Berlim. Ela está contente com a bolsa de estudo, e o dinheiro do apartamento ajudou muito.

(A Partilha, Miguel Falabella, 1989)

\section{[+h/-espec]}

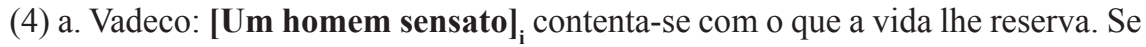
lh $_{\mathbf{i}}$ falta o pão, a saúde, a moradia, $\varnothing_{\mathbf{i}}$ sofre, mas não se revolta. $\varnothing_{\mathbf{i}}$ Toma a responsabilidade sobre si mesmo.

( $A$ Vida tem Três Andares, Humberto Cunha, 1938)

b. Dona Irene: Não é culpa dele, Holly. Está provado que, se [a criança $]_{i}$ não recebe uma alimentação eficaz, ela fica em desvantagem para o resto da vida.

[-h/+espec]

(No coração do Brasil, Miguel Falabella, 1992)

(5) a. Ambrósio : Juquinha, gostas $\mathrm{d}[\text { esta roupa }]_{\mathrm{i}}$ ?

Juca : Não, $\varnothing_{\mathrm{i}}$ não me deixa correr, é preciso levantar assim...

(O Noviço, Martins Pena, 1845)

${ }^{16}$ A análise de Cyrino focaliza os objetos de terceira pessoa; outros estudos sobre os complementos acusativos de primeira e segunda pessoa, inerentemente [+hum/+esp], mostram que eles são necessariamente expressos, a menos que recuperados do contexto precedente, o que os torna anafóricos (cf. Duarte e Ramos, 2015). 
b. Ladrão: Aliás, eu não assaltei [a casa do lado] $]_{i}$, porque ela $a_{i}$ está na jurisdição do $14^{\circ}$ Distrito.

(Do tamanho de um defunto, Millôr Fernandes, 1955)

[-h/-espec]

(6) Padre Mestre: [Incômodos $]_{i}$ ? Para eles ${ }_{i}$ nascemos nós... $\varnothing_{i}$ passam desapercebidos, e demais $\emptyset_{\mathrm{i}}$ ficam de muros para dentro.

(O Noviço, Martins Pena, 1945)

b. Cláudio: Vivemos numa constante espera de $\left[{\text { felicidade }]_{i} \text { e quando ela }}_{i}\right.$ chega não a enxergamos!...

(A Vida tem Três Andares - Humberto Cunha, 1938)

A análise de Duarte, Mourão e Santos (2012) mostra que, de fato, sujeitos com antecedentes com a combinação [+hum/+esp] caminham mais rapidamente em direção ao pronome pleno do que aqueles com a combinação [-hum/+esp]. Ambas as combinações com o traço [-esp], ilustradas em (4) e (6) acima, são pouco frequentes na amostra e não permitem concluir que há de fato aumento de sujeitos expressos com esse traço. Entretanto, dentre as quatro ocorrências atestadas nas peças dos anos 1990 que exibem a combinação [+hum/-esp] três apresentam o sujeito expresso, enquanto nos raros dados com à combinação do traço [-hum/-esp], o sujeito nulo é praticamente categórico.

Assim, a Figura 3, a seguir, exibirá apenas a evolução do sujeito expresso com as combinações com o traço [+esp] (ver distribuição geral dos dados na Tabela 2 de Duarte, Mourão e Santos, 2012:16). Incluímos ainda na Figura 3 um tipo de sujeito não mencionado na hierarquia referencial, tradicionalmente classificado como indeterminado, que tem igualmente o traço inerentemente [+hum], embora sua referência seja [+arbitrária/+genérica], o que o aproxima dos [-esp] de terceira pessoa $^{17}$. Entre esses sujeitos nos interessam aqueles representados por formas verbais na $3^{\mathrm{a}}$. pessoa do plural (eles), $1^{\mathrm{a}}$. pessoa do plural (nós), pela segunda pessoa do singular (você) e pela $3^{\mathrm{a}}$. pessoa do singular (a gente). Dessas estratégias, apenas uma é apresentada nas gramáticas tradicionais como forma de indeterminação de um agente, devendo apresentar o pronome nulo - o uso da terceira pessoa do plural $^{18}$. Os dados de Vargas (2012), com base na mesma amostra, revelam que, como previsto pela hierarquia referencial, esses sujeitos já tendem a apresentar o pronome expresso em competição com o sujeito nulo, como ilustramos em (7):

(7) a. Rosa: Ora, mamãe, é muito dinheiro. Ainda mais com a situação de reviravolta no País, você nunca vai receber esse dinheiro. É dinheiro demais! Eles ${ }_{\text {arb }}$ não pagam!

(Um elefante no caos, Millôr Fernandes, 1955)

${ }^{17} \mathrm{O}$ que distingue sujeitos com o traço [+/-esp] e [ + arb] é que apenas os primeiros podem ser retomados, podendo ser retomados por um pronome pessoal (ele(s)/ela(s) - "[O aluno]i sabe que [ele] i vai ter de se submeter a uma prova difícil".

${ }^{18}$ Não ignoro o fato de que a terceira pessoa do plural em geral exclui o falante, distinguindo-se das demais. O que interessa aqui é a representação do sujeito indeterminado. 
b. Jeremias: Para que não $\varnothing_{\text {arb }}$ percamos o ritmo da vida é indispensável $\varnothing_{\text {arb }}$ seguramos bem o nosso par.

(O simpático Jeremias, Gastão Tojeiro, 1919)

c. Neiva: A senhora não devia ter falado com ela assim, Dona Irene. A gente fica muito sensível quando $\varnothing_{\mathrm{i}}$ está de barriga.

(No coração do Brasil, Miguel Falabella, 1992)

b. Melanie: Tem uma outra técnica, que é muito usada, hoje em dia. O segredo é não se importar. Se você $\hat{a r b}_{\text {ão se importar, você }}$ arb acaba dormindo.

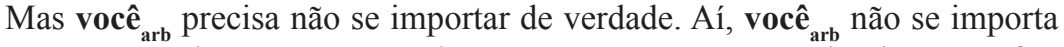
se matam crianças para vender órgãos para países mais ricos, vocêe ${ }_{\text {arb }}$ simplesmente não se importa.

(Como encher um biquíni selvagem, Miguel Falabella, 1992)

Vejamos, na Figura 3, as linhas para os sujeitos de terceira pessoa [+hum/+esp], os [-hum/+esp] e os de referência arbitrária:

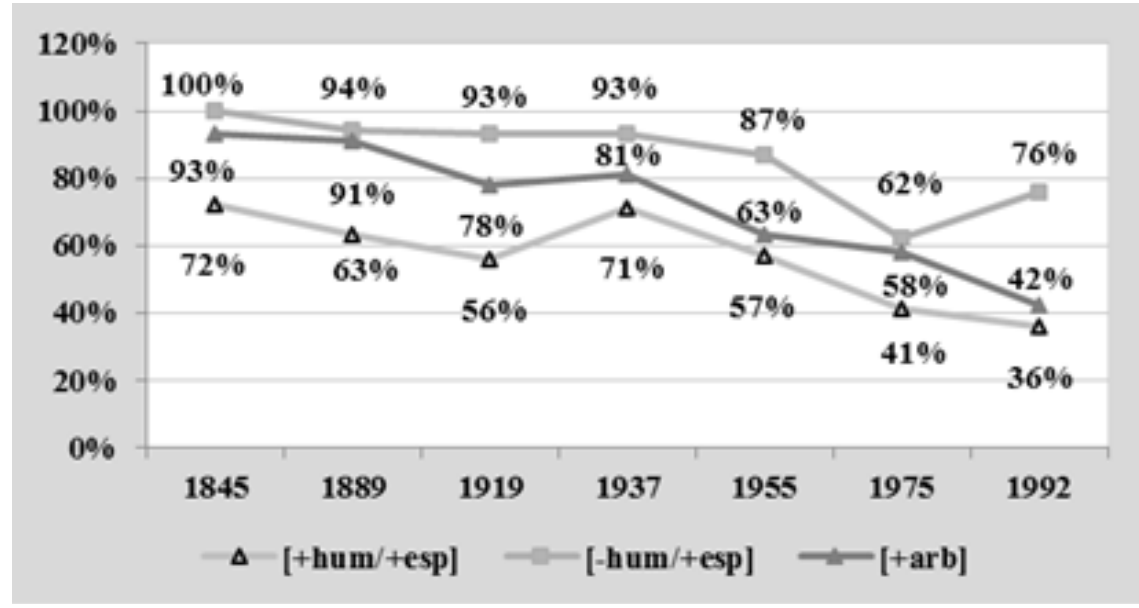

Figura 3. Sujeitos referenciais nulos de $3^{\text {a }}$. pessoa (vs. pronomes expressos) segundo o traço e sujeitos nulos de referência arbitrária (vs. pronomes expressos)

(Adaptado de Duarte, Mourão e Santos, Fig. 3,2012:39 e Vargas,

Fig.2, 2012:60)

Acompanhando a linha mais baixa, que representa o percurso do sujeito de terceira pessoa com os traços [+hum/+esp], vemos que esta é a que apresenta maior redução nos índices de sujeitos nulos, chegando a 36\% de ocorrências na última sincronia. Embora mantendo-se a certa distância, a linha que representa os sujeitos de referência arbitrária parte de $93 \%$ de pronomes nulos para, a partir da segunda metade do século 20 , chegar a $42 \%$, o que se deve em grande parte, mas não apenas, à implementação de a gente e você, as formas também preferidas pelo PB oral para referência definida e arbitrária. 
Quanto aos sujeitos de terceira pessoa, com o traço [-hum/+esp], temos um contexto de resistência, que ajuda a entender o resultado de Duarte (1993) reproduzido na Figura 2. Há, entretanto, uma importante inovação que não poderia ser percebida se a perspectiva teórica que orienta a análise não levasse em conta o PB no contexto das línguas românicas: línguas [+SN] não representam referentes [-humanos] com pronomes pessoais, recorrendo a demonstrativos, por exemplo. Os pronomes expressos com esse feixe de traços são, de fato, pouco frequentes na amostra, alcançando em números absolutos, uma, duas e três ocorrências nos períodos II (anos 1880, III (anos 1920) e IV (anos 1930), respectivamente. Em apenas dois deles se pode dizer que temos um caso de personificação, numa tentativa do falante de fazer graça ou dramatizar sua fala $(8 \mathrm{a}, \mathrm{b})$. Nas demais, o que temos é um claro indício de que não há restrição a um pronome expresso com esse feixe de traços:

(8) a. Madalena: Como apanhou [esse reumatismo $]_{i}$ ?

Félix: Não o apanhei: ele veio por si. É a ferrugem da idade.

(O simpático Jeremias, Gastão Tojeiro, 1919)

b. Vadeco : Ouve aquela música ?... É o prognóstico [da sua felicidade $]_{i}$ ! Ela está muito doente...

(A vida tem três andares, Humberto Cunha, 1938)

c. Douglas: Quem é então o dono [da jazida $]_{\mathrm{i}}$ ?...

Artur: É um tal de Maneco, que mora em São Paulo. Bernardo é apenas o administrador da fazenda em que ela ${ }_{i}$ está situada.

(O simpático Jeremias, Gastão Tojeiro, 1919)

d. Dilermando: Como recurso imediato, ponho a sua disposição [a casa $]_{i}$ que possuo lá em Olaria. Por sorte, $[\text { ela }]_{\mathrm{i}}$ está atualmente vaga...

(O troféu, Armando Gonzaga, 1937)

Em nenhum dos casos se pode argumentar que o pronome ocorre para evitar uma interpretação ambígua ou para expressar contraste. O mesmo se vê em peças da segunda metade do século 20, quando, embora ainda predominem os sujeitos nulos, o percentual de pronomes expressos já alcança índices mais expressivos. O exemplo em (9), que exibe um pronome expresso tendo um antecedente como tópico discursivo, atesta a implementação mais lenta, mas consistente, de pronomes pessoais com o traço [-hum]:

(9) a. Armando: Por que você não aprontou [o almoço $]_{i}$ na hora?

Cristina: Ele está pronto. Só que eu não vou botá-lo na mesa.

(A mulher integral, C. Eduardo Novaes, 1775)

b. E [as historinhas infantis $]_{i}$ ? Elas ${ }_{i}$ estão ficando tão avançadas que semana passada um amigo meu estava lendo um livro para o filho e de repente descobriu que a Nova Cinderela não calça mais 32.

(Confidências de um espermatozoide careca, C. Eduardo Novaes, 1984) 
Da mesma forma que o traço semântico, a análise de Duarte, Mourão e Santos (2012) mostra o padrão sentencial atuando no processo de mudança (cf. Figura 2, op.cit: 33). Com um antecedente distante ou em outra função o sujeito já é quase categoricamente expresso nas duas últimas sincronias, enquanto o antecedente com a mesma função, esteja ele na oração adjacente ou na principal, ainda constitui um contexto de resistência no processo de mudança. Ainda assim, os nulos e expressos já empatam no caso de um antecedente no contexto adjacente. Em resumo: os contextos em que um pronome é proibido numa língua $[+\mathrm{SN}]$ do grupo românico - sujeitos mais acessíveis sintaticamente e sujeitos [-hum] - são os contextos de maior resistência à implementação da mudança.

Seguindo a hierarquia referencial, nos defrontamos com o sujeito proposicional (ou neutro), que retoma uma oração ou porção maior do discurso, que ilustramos em $(10)^{19}$ :

(10) a. Júlia: Você esperou-o vestida de quê?

Cristina: De coelhinho da Playboy.

Júlia: Não sei se $\boldsymbol{O}$ foi uma boa idéia.

(A mulher integral, Carlos Eduardo Novaes, 1975)

$(\boldsymbol{O}=$ o fato de Cristina ter esperado o marido vestida de coelhinho da Playboy)

b. Holly: Eu serei Verônica!

Dona Irene: Isso é um sacrilégio. Faça o favor de tirar essa roupa.

(No coração do Brasil, Miguel Falabella, 1992)

(isso $=\mathrm{o}$ fato de Holly, um travesti, querer representar Verônica na encenação da Paixão de Cristo)

Nesse contexto, a análise de Duarte, Mourão e Guimarães (2012) confirma que a mudança caminha ainda mais lentamente, o que pode se dever, além da menor referencialidade, ao fato de que o verbo ser é o mais frequente nessas estruturas e tem se mostrado um importante contexto de resistência dos sujeitos nulos em geral. O que os resultados sugerem é uma estável, contrariando a proposta de competição de Kroch, que não permite esse tipo de variação por longos períodos de tempo.

A investigação sobre a posição estrutural do sujeito com base nas peças continua em Duarte (2012) seguindo a hierarquia referencial, chegando ao seu ponto extremo, onde se encontram os sujeitos não referenciais (ou expletivos). Ora, a teoria linguística que orienta a pesquisa, pelo menos na proposição inicial de Princípios e Parâmetros, nos levaria a buscar algum tipo de mudança em direção talvez ao surgimento de um sujeito expletivo lexical, como adquiriu o francês

${ }^{19}$ Devemos a Paredes Silva (1985) os primeiros trabalhos variacionistas acerca de tais sujeitos, desenvolvidos em associação com o quadro da Teoria Funcionalista. Devemos à autora a tradução do termo 'extended reference subjects', proposto por Haliday e Hasan (1979), como "sujeitos de referência estendida". Outros estudos desenvolvidos sobre o tema, dentro dessa associação, podem ser vistos em Paredes Silva e Oliveira (2014) entre outros. 
desde estágios mais antigos da sua formação (Il pleut, Il semble) ou o espanhol falado por uma camada da classe popular da República Dominicana nos dias atuais (ello llueve, ello parece), como apontou Toribio $(1996)^{20}$. Isso, entretanto, não é o que ocorre no PB.

À luz do quadro atual de Princípios e Parâmetros, que se esforça por acomodar a grande variação observada em diferentes línguas em "hierarquias de parâmetros" (cf. Biberauer et al. 2010 e Roberts, 2012), poderíamos dizer que o PB se ajusta a um parâmetro positivamente marcado em relação aos sujeitos expletivos nulos e negativamente marcado em relação aos sujeitos referenciais nulos. No entanto, o que observamos no PB é uma tendência a evitar expletivos nulos, seja com o alçamento de constituintes para a posição estrutural do sujeito seja com a inserção de pronomes demonstrativos ou a pessoalização de sentenças existenciais. Os capítulos que se seguem em Duarte (2012), focalizando as construções impessoais, mostram o comportamento de estruturas com verbos inacusativos que selecionam um DP e os que selecionam uma oração complemento: no caso dos primeiros, nota-se uma tendência a evitar V DP com DPs lexicais que tenham o traço [+hum] enquanto resistem os DPs lexicais com o traço [-hum] (Santos e Soares da Silva, 2012) e no caso dos verbos que selecionam um complemento oracional, notase uma competição entre o expletivo nulo e o alçamento do sujeito da oração encaixada (Henriques, 2012). Quanto às existenciais, não há dúvida de que a vitória de ter sobre haver abre amplo espaço para a pessoalização dessas estruturas (Marins, 2012).

Ao lado dessas análises diacrônicas, temos fortes evidências sincrônicas de que os sujeitos referenciais se encontram em estágio bem mais avançado em direção aos pronomes expressos (Duarte, 1995; Soares da Silva, 2011, entre muitos outros estudos). A Figura 4, a seguir, mostra os percentuais para sujeitos referenciais expressos na fala culta carioca, ao longo da hierarquia referencial:

${ }^{20}$ Uma visita à República dominicana, área da capital Santo Domingo, me revelou que, de fato, estamos diante de uma mudança "de baixo para cima", certamente um efeito colateral do preenchimento dos sujeitos referenciais. A pressão escolar é, entretanto, muito forte em relação a essas estruturas. Os falantes reconhecem que usam essas formas apenas em família porque não é uma forma “permitida pela Real Academia Espanhola". Na fala espontânea, mesmo fora do círculo familiar, os exemplos são numerosos. 


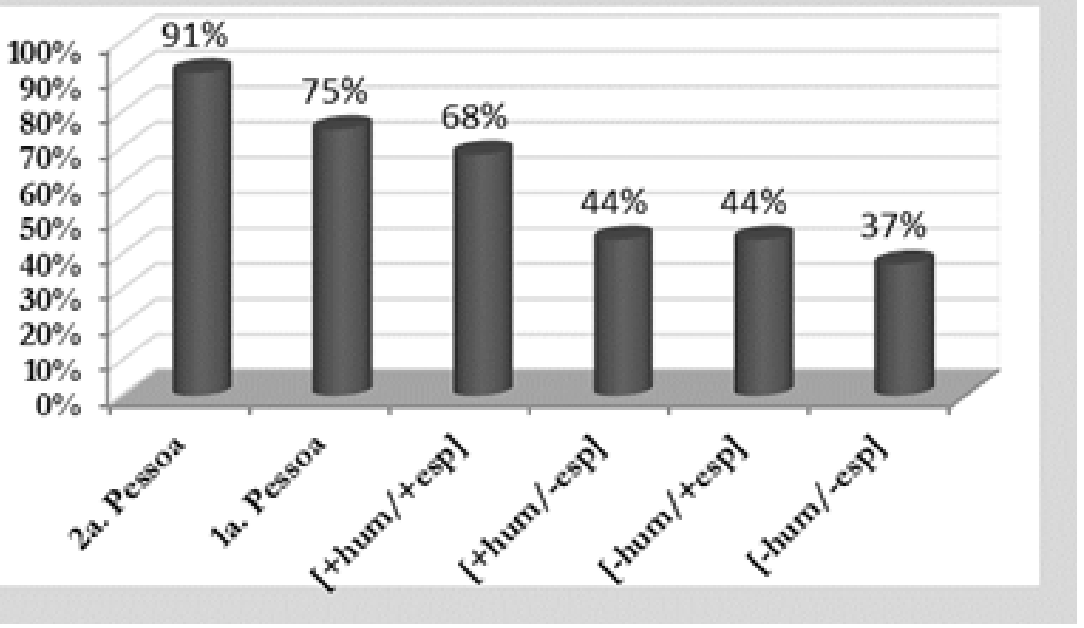

Figura 4. Sujeitos expressos (vs nulos) na fala carioca, segundo o traço do referente $(\%)$. (Apud Duarte, Mourão e Santos, Fig. 4,2012:42)

Quanto aos sujeitos não argumentais, o alçamento de constituintes para a posição estrutural de sujeito nessas estruturas, que não selecionam um argumento externo, muito particularmente em construções com verbos inacusativos, é uma inovação em progresso. Embora se possa contestar o estatuto sintático do argumento interno de inacusativos que selecionam um DP, temos fortes evidências de que existe uma mudança em curso, que não pode ser atribuída ao acaso. Além de sensível aumento de DP V em relação a V DP, Duarte e Kato (2014) encontram predomínio de alçamento de genitivos sempre que os DPs apresentam tal estrutura, gerando a ordem GEN V DP (Esses rios subiram o nível $\left[t_{i}\right]$ ). ${ }^{21}$ Essas estruturas, intrinsecamente ligadas a uma remarcação no valor do PSN, aparecem como uma solução encontrada pelo sistema para evitar expletivos nulos através de elementos referenciais - uma solução que deve estar relacionada a uma característica das línguas orientadas para o discurso ou línguas de proeminência de tópico, nas quais não há lugar para elementos foneticamente realizados sem conteúdo semântico (cf. Li e Thompson, 1976).

${ }^{21}$ A análise de Kato e Duarte (2014) utiliza sites de reclamação da internet, uma forma de contornar a dificuldade de encontrar as estruturas em entrevistas sociolinguísticas. Labov (2006 [1966]) considera a utilização de dados fontes anônimas, coletados de maneira informal uma importante ferramenta na pesquisa sociolinguística. 


\section{CONSIDERAÇÕES FINAIS}

Neste artigo, procurei mostrar que a Teoria da Variação e Mudança Linguística tem sido tratada como se fosse uma teoria linguística, capaz de fornecer ela mesma o suporte ou componente gramatical indispensável para pôr em prática o modelo teórico de estudo da mudança que ela de fato propõe. Mostrei que a pesquisa variacionista teve início no Brasil justamente se voltando para a variação morfossintática em associação com a Teoria Funcionalista. Foi a associação com pressupostos da Teoria Gerativa - motivada por evidências empíricas de que havia processos de mudança na marcação de valores paramétricos em curso - que levantou polêmicas, porque não havia no âmbito dos estudos gerativistas qualquer preocupação com estudos de mudança, o que veio a ocorrer a partir de fins dos anos 1980 .

Apesar das ressalvas, em minha opinião equivocadas, em relação a tal associação, busquei mostrar que a proposta de Tarallo e Kato nunca reduziu a Teoria da Variação a uma simples metodologia; antes, a associação com a Teoria de Princípios e Parâmetros tem permitido responder a todas as questões formuladas pelo modelo de estudo da mudança da teoria da variação, porque oferece ao pesquisador uma descrição da sintaxe das línguas tão sofisticada a ponto de permitir relacionar fenômenos superficiais aparentemente desvinculados. Por outro lado, os resultados dos estudos desenvolvidos à luz de tal associação têm contribuído para as revisões por que tem passado a Teoria de Princípios e Parâmetros: os dados do PB têm permitido atestar importantes efeitos das mudanças sintáticas em curso, o que dá à pesquisa variacionista associada à sintaxe gerativa no Brasil um lugar de destaque no âmbito dos estudos de mudança linguística.

\section{REFERÊNCIAS BIBLIOGRÁFICAS}

AVELAR, J. O. (2006). Gramática, competição e padrões de variação: casos com ter/haver e de/em no português brasileiro. Revista de Estudos da Linguagem, 4, p. 99-144.

BARBOSA, P.; M. E. L. DUARTE; M. A. KATO. (2005). Null Subjects in European and Brazilian Portuguese. Journal of Portuguese Linguistics, 4: p. 11-52.

BIBERAUER, T. et al. (2010). (Eds.). Parametric Variation: null subjects in Minimalist theory. Cambridge: C.U.P.

BERLINCK, R. de A. (1996). The Portuguese dative. In: W. BELLE; W. LANGENDONCK (Eds.) The dative: Descriptive studies, vol. 1. Amsterdam/ Phidadelphia: John Benjamins Publishing Company, p. 119-149.

BORGES NETO, J. (2004). A incomensurabilidade e a "compatibilização" de teorias. In: J. BORGES NETO. Ensaios de Filosofia da Linguística. São Paulo: Parábola Ed.

BRAGA, M. L. (1978). Concordância de número do Sintagma Nominal no Triângulo Mineiro, PUCRJ. 
CHOMSKY, N. (1981). Lectures on Government and Binding. Dordrecht, Foris.

COTE, S. A. (1996). Grammatical and discourse properties of null arguments in English. Tese (Doutorado), University of Pennsylvania.

CYRINO, S. (1993). Observações sobre a mudança diacrônica no português do Brasil: objeto nulo e clíticos. In I. Roberts; M. A. Kato (Orgs.), p. 163-184.

CYRINO, S. (1997). O objeto nulo no português do Brasil - um estudo sintático-diacrônico. Londrina: Editora da UEL.

CYRINO, S.; DUARTE, M. E. L.; KATO, M. A. (2000). Visible subjects and invisible clitics in Brazilian Portuguese. In: M. A. KATO; E. V. NEGRÃO. (Eds.), p. 55-73

DUARTE, M. E. L. (1993). Do pronome nulo ao pronome pleno: a trajetória do sujeito no português do Brasil. In: I. ROBERTS; M. A. KATO. (Orgs), p. 107-128.

DUARTE, M. E. L. (1995). A perda do princípio "Evite Pronome" no português brasileiro. Tese (Doutorado), UNICAMP.

DUARTE, M. E. L. (2000a). Variação sintática e mudança paramétrica. Gragoatá, v. 9, p. 75-84.

DUARTE, M. E. L. (2000b). The loss of the ‘Avoid Pronoun’ Principle in Brazilian Portuguese. In: M. A. KATO; E. V. NEGRÃO (Eds.), p. 17-36.

DUARTE, M. E. L. (2003). A evolução na representação do sujeito pronominal em dois tempos. In: M.C. Paiva e M. E. L. DUARTE (Orgs.), p. 115-128.

DUARTE, M. E. L. (2007). Sobre outros frutos de "um projeto herético": o sujeito expletivo e as construções de alçamento. In: A. de Castilho; Torres Morais, M. A; R. Lopes; S. Cyrino (Orgs) Descrição história e aquisição na história do português brasileiro. Campinas: Pontes, p. 35-48.

DUARTE, M. E. L. (2012). O sujeito em peças de teatro (1833-1992): Estudos diacrônicos. São Paulo, Parábola Ed.

DUARTE, M. E. L. (2013). O papel da sociolinguística na descrição da gramática da escrita contemporânea. In: M. A. Martins; M. A. Tavares (Orgs.). Contribuições da Sociolinguística e da Linguística Histórica para o ensino de língua portuguesa. Natal: Ed. da UFRN, p. 117-143.

DUARTE, M. E. L.; MOURÃO, G.; SANTOS, H. (2012). Os sujeitos de terceira pessoa: revisitando Duarte 1993. In: M. E. L. DUARTE, p. 21-44.

DUARTE, M. E. L.; G. MOURÃO e L. GUIMARÃES. (2012). A retomada dos sujeitos proposicionais: categoria vazia ou demonstrativo? In: M. E. L. DUARTE, p. 69-82.

DUARTE, M. E. L.; FREIRE, G. C. (2014). Como a escrita padrão recupera formas em extinção e recupera formas inovadoras. In: M. C. PAIVA e C. A. GOMES (Orgs.), p. 115-135.

DUARTE, M. E. L.; KATO, M. A. (2014). Variation in Syntax: null expletives and raised constituents in Brazilian Portuguese. Comunicação, NWAV43, Chicago.

DUARTE, M. E. L.; RAMOS, J. (2015). Variação nas funções acusativa, dativa e reflexiva. In: M. A. Marins e J. Abraçado (Orgs.). Mapeamento Sociolinguístico do Português Brasileiro: teoria, descrição e análise. São Paulo: Contexto. 
EMMERICH, C. (1984). A língua de contato no Alto Xingu. Museu Nacional, Tese (Doutorado), UFRJ.

FREIRE, G. C. (2000). Os clíticos de terceira pessoa e as estratégias para sua substituição na fala culta brasileira e lusitana. Dissertação (Mestrado), UFRJ.

FIGUEIREDO SILVA, M. C. (2000). Main and embedded sull subjects in Brazilian Portuguese. In: M. A. KATO; E. V. NEGRÃO, E. V. (Orgs.), p. 127-145.

GOMES, C. A. (2003). Variação e mudança na expressão do dativo no português brasileiro. In: M. C. PAIVA; M. E. DUARTE (Orgs.), p. 81-96.

HAEGEMAN, L. (1990). Understood subjects in English diaries, Multilingua, 9, p. 157-159.

HALLIDAY, M. A. K.; HASAN, R. (1979). Cohesion in English, London: Longman.

HENRIQUES, F. (2012). Construções com verbos de alçamento que selecionam um complemento oracional. In: M. E. L. DUARTE, p. 101-120.

HENRY, A. (2002). Variation and Syntactic Theory. In: J. K. Chambers et al. (Orgs.). The Handbook of Language Variation and Change. Oxford, Blackwell, p. 266-282.

KATO, M. A. (1999). Os frutos de um projeto herético: parâmetros na variação intra-linguistica. In: D. da HORA; E. CHRISTIANO (Orgs.) Estudos Lingüisticos: realidade brasileira. João Pessoa: Idéia, p. 95-106.

KATO, M. A. (2005). A gramática do letrado: questões para a teoria gramatical. In: M. A. MARQUES; E. KOLLER; J. TEIXEIRA; S. A. LEMOS (Orgs). Ciências da Linguagem: trinta anos de investigação e ensino. Braga: CEHUM (U. do Minho), p. 131-145.

KATO, M. A.; TARAllO, F. Anything YOU can do in Brazilian Portuguese. In O. Jaeggli; C. SilvaCorvalan (Eds.) Studies in Romance Linguistics. Dordrecht: Foris.

KATO, M. A.; NEGRÃO, E. V. (Eds.). (2000). Brazilian Portuguese and the Null Subject Parameter. Frankfurt/Madrid: Vervuert/Iberoamericana.

KATO, M. A.; TARAllo, F. (2003). The loss of VS Syntax in Brazilian Portuguese. In: I. SCHLIEBEN-LANGE, I. V. KOCH, K. JUNGBLUTH (Hrsg.) Dialog zwischen den Schulen. Münster: Nodus Publikationen, p. 101-129.

KROCH, A. (1989). Reflexes of grammar in patterns of language change. Language Variation and Change, 1, p. 199-244.

KROCH, A. (1994). Morphosyntactic variation. In: K. BEALS. Proceedings of the thirtieth annual meeting of the Chicago Linguistics Society. v. 2, p. 180-201.

KROCH, A. (2001). Syntactic Change. In BALTIN and COLLINS (Eds). The Handbook of contemporary Syntactic Theory. Mass: Blackwell, p. 699-729.

LABOV, W. (2006 [1966]). The social stratification of (r) in New York City department stores, UK: Cmbridge University Press, p. 40-57.

LAVANDERA, B. (1971-1982, 1978). Where does the sociolinguistic variable stop? Language in Society, 7, 2. 
LEMLE, M.; NARO, A. (1977). Competências básicas do português. Rio de Janeiro: Mobral/MEC.

LI, Ch. e THOMPSON, S. (1976). Subject and topic: a new typology of language. In C. N. Li. (Org). Subject and Topic. New York: Academic Press Inc.

LIGHTFOOT, D. (1991). How to set parameters. Cambridge, MA: MIT Press.

LIRA, S. de A. (1982). Nominal, Pronominal and Zero Subject in Brazilian Portuguese. Tese (Doutorado), University of Pennsylvania.

LOPES, R. E. V. (2003). The production of subject and object in Brazilian Portuguese by a Young child. Probus, v. 15. N. 1, p. 121-144.

MARINS, J. (2009). O Parâmetro do Sujeito Nulo: uma análise contrastiva entre o português e o italiano. Dissertação (mestrado), UFRJ.

MARINS, J. (2012). As sentenças existenciais no PB: ecos da mudança na marcação paramétrica. In: M. E. L. DUARTE, p. 83-100.

MARINS, J. (2013). As repercussões da remarcação do parâmetros do Sujeito Nulo: um estudo diacrônico das sentenças existenciais com ter e haver no PB e no PE. Tese (Doutorado), UFRJ.

MODESTO, M. (2000). Null Subjects without "rich" agreement. In: M. A. KATO; E. V. NEGRÃO, E. V. (Orgs.), p. 147-174.

MODESTO, M. (2008). Topic prominence and null subjects. In: T. Biberauer (ed.). The limits of syntactic variation. Amsterdam: John Benjamins, p. 375-406.

MOLLICA, C. (1977). Estudo da cópia nas construções relativas em português. Dissertação (Mestrado), PUC-RJ.

MOREIRA DA SILVA, S. (1983). Études sur la Symétrie et l'Asymétrie SUJET/OBJET dans le Portugais du Brésil. Université de Paris VIII, Tese (Doutorado).

MOURA NEVES, M. H. de. (1999). Estudos Funcionalistas no Brasil. Revista DELTA, v. 15, 71-104.

OMENA, N. (1978). Pronome pessoal de terceira pessoa: suas formas variantes em função acusativa. Dissertação (Mestrado), PUC-RJ.

PAGOTTO, E. G. (1998). Norma e condescendência; ciência e pureza. Língua e Instrumentos Linguísticos, 1 (2). p. 49-68.

PAGOTTO, E. G. (2013). A norma da constituição e a constituição da norma no século XIX. Revista LETRA, Rio de Janeiro, UFRJ, v.1, p. 31-50.

PAGOTTO, E. G. (2006). Sociolinguística. In: C. C. PFEIFFER e J. H. NUNES (Orgs.). Introdução às Ciências da Linguagem - Linguagem, História e Conhecimento. Campinas. Pontes, p. 49-72.

PAIVA, M. C. e DUARTE, M. E. L. (Orgs.). (2003). Mudança Lingüística em Tempo Real. Rio de Janeiro: Contra Capa/Faperj.

PAIVA, M. C e GOMES, C. A. (Orgs.). (2014). Dinâmica da Variação e Mudança na Escrita. Rio de Janeiro: ContraCapa. 
DUARTE - Avanços no estudo da mudança sintática...

PAREDES SILVA, V. L. (1985). É isso aí: verbo ser e demonstrativos em função coesiva no português. PUCRJ e UFRJ. Comunicação apresentada durante o Encontro Nacional de Linguística, PUCRJ.

PAREDES SILVA, V. L. (1988). Cartas cariocas: A variação do sujeito na escrita informal. Tese (Doutorado), UFRJ.

PAREDES SILVA, V. L.; OLIVEIRA, A. (2014). "É isso aí": a variação na referência estendida em diferentes gêneros de escrita. In: M. C. PAIVA e C. A. GOMES (Orgs.), p. 45-68.

RIZZI, L. (1982). Issues in Italian Syntax. Dordrecht: Foris.

RIZZI, L. (1988). The new comparative syntax: principles and parameters of universal grammar. Ms.

RIZZI, L. (1997) A parametric approach to comparative syntax: properties of the pronominal system. In: L. HAEGEMAN (Org.). The new comparative syntax, London: Longman, p. 268-285.

ROBERTS, I. (1993). Verbs and Diachronic Syntax. Dordrecht: Kluwer.

ROBERTS, I. (2012). Macroparameters and minimalism: a program for comparative research. In: C. GALVES, CYRINO, S.; LOPES, R.; SÂNDAlO, F.; AVELAR, J. Parameter Theory and Linguistic Change. Oxford: Oxford University Press, p. 320-335.

ROBERTS, I. \& KATO, M. A. (1993). Português Brasileiro: uma viagem diacrônica. Campinas: Pontes.

SANTOS, D.; SOARES DA SILVA, H. (2012). A ordem V-DP/DP-V com verbos inacusativos. In: M. E. L. DUARTE, p. 121-142.

SCHERRE, M. (1978). A regra de concordância de número no Sintagma Nominal em português, Dissertação (Mestrado), PUC-RJ.

SOARES DA SILVA, H. (2011). Evidências da mudança paramétrica em dados da Língua-E: o sujeito pronominal no português e no espanhol. Tese ((Doutorado), UFRJ.

TARALLO, F. (1983). Relativization Strategies in Brazilian Portuguese. Tese (Doutorado), University of Pennsylvania.

TARAllO, F. (1987). Por uma Sociolinguística Românica "Paramétrica": Fonologia e Sintaxe. Ensaios de Linguística, UFMG, v. 13, p. 51-84.

TARALlO, F. (Org.). (1989). Fotografias Sociolinguisticas. Campinas: Pontes/Ed. da Unicamp.

TARALLO, F. (1993). Diagnosticando uma gramática brasileira: o português d'aquém e d'além mar ao final do século XIX. In: I. ROBERTS, I. e M. A. KATO (Orgs). p. 69-105.

TARALLO, F. e KATO, M. A. (2007). Harmonia trans-sistêmica: variação inter e intralingüística. In: Preedição 5. Campinas, Unicamp. p. 315-353, 1989. [Artigo reeditado em Diadorim, Revista do Programa de Pós-Graduação em Letras Vernáculas da UFRJ, vol. 2, p. 13-42.].

TORIBIO, J. (1996). Dialectal Variation in the licensing of null referential expletive subjects. In: Parodi; C., Quicoli, C.; Saltarelli, M.; Zubizarreta, M. L. (Eds.) Aspects of Romance Linguistics. Washington, DC: Georgetown University Press, p. 409-432. 
Cadernos de ESTUDOS LINGǘsSTICOS (57.1) - Jan./Jun. 2015

WEINREICH, U.; LABOV, W. \& HERZOG, M. (1986). Empirical Foundations for a Theory of Language Change In: W. Lehman and Y. Malkiel (Orgs.). Directions for historical linguistics. Austin: University of Texas Press, p. 97-195. [Artigo traduzido por M Bagno. Fundamentos empíricos para uma teoria da mudança linguística. São Paulo: Parábola Editorial, 2006.]. 